\title{
Analysis of satisfaction factors at urban transport interchanges: Measuring travelers' attitudes to information, security and waiting
}

\author{
David Lois \\ Social Psychology Department, UNED, Spain \\ Andrés Monzón, Sara Hernández \\ Transport Research Centre, TRANSyT-UPM, Spain
}

\begin{abstract}
Transport interchanges can be considered as a node, where people transfer from one mode to another, and as a place to stay, using facilities and services as well as waiting areas. Reducing disruption of transfer in multimodal trips is a key element for assuring seamless mobility in big cities.
\end{abstract}

Based on previous research (Hernández \& Monzón, 2016) this paper aims to explore the predictive capacity of attitudes towards several service factors on general satisfaction with transport interchange. Complementary, it was analyzing how personal and trip characteristics are related to evaluation of some variables, and examining the influence of waiting time on the perceived quality. To that end, a two steps methodology was conducted (personal and on-line interview) in a representative sample of 740 users (54\% female, 55\% work purpose trip). We performed path analysis to test the model showing a satisfactory statistical fit.

The model developed show good performance for predicting general satisfaction at Moncloa Transport Interchange (Madrid, Spain). The outputs of the model indicate that Information and Safety and Security factors predicted $49 \%$ of general satisfaction. Furthermore, the results showed also a strong association between evaluation of Design and Environmental quality, factors that not affect directly general satisfaction but do so through Information and Safety \& Security perception, acting the last as mediator variables.

Nevertheless, spending time queuing inside the interchange show a negative influence on Information and Safety \& Security, while age of participants affect negatively to Information, which mean that elder have some cognitive accessibility problems. Moreover, our data shows gender differences in safety perception, since women feel less safe (particularity the youngest) inside the interchange. The results indicate a number of priority measures to enhance perceived quality and efficiency of interchanges. 


\section{INTRODUCTION}

The growing demand for mobility in the cities, with proximity and connectivity as core factors, is boosting mass transit solutions leading by public transport authorities (IAPT, 2015). In this scenario, intermodality is a key factor of daily mobility and its identified as the means for ensuring seamless travel at metropolitan and urban level. In Europe, intermodality appearing in European Commission's White Paper on Transport Policy of 2001 (COM, 2001) and subsequently in 2006, with the Mid-Term Review of the Transport White Paper of 2001 (COM, 2006), the Action Plan for the Deployment of Intelligent Transport Systems in 2008 (COM, 2008), and the EU Transport Policy in 2011 (COM, 2011). The development of transport interchanges is a frequent response to user's intermodality needs, and there is a significant interest in understanding how public transport stations and hubs can improve its service based in the user's attitudes.

Focused on the general characteristics of these infrastructures, three different zones can be distinguished within an interchange from the user's point of view, each with a different focus of services (Wilson and Yariv, 2011): the Access/Egress Zone; Transport/Transfer Zone, and the Facilities and Retail Zone. Providing multiple access/egress points for different modes can reduce the likelihood of access conflicts (Monzón and Di Ciommo, 2015). Transport/Transfer Zone is where users are waiting for transport modes or transferring. As noted by NSW Ministry of Transport (2008), there is clear evidence that time spent waiting and transferring are the main reasons why public transport customers are averse to moving between modes. Harmer et al. (2014) highlighted that design and operation should be focused around minimizing distances between modes and reducing journey times. Finally, the Facilities/Retail Zone is the area where users spend time doing activities such as shopping or eating while they wait for their transfer. This zone should also provide real time information to ensure users are kept up to date with any delays or changes to their travel (Monzón and Di Ciommo, 2015).

Taking as a first step the previous results obtained by Hernández \& Monzón (2016), the general purpose of this research is to analysis the main dimensions (and functions) that explain the satisfaction of the users of a transport interchange, deepening in the relations that these dimensions maintain with each other. In terms of transport policy, two main reasons support the research of satisfaction level of transport interchanges users. Firstly, a satisfactory stay within the interchange contributes to improve travel experience in transit as a whole, progressively strengthened this transport mode choice. Secondly, satisficed users, as those who most valued its instrumental and emotional benefits, are the best prescribers of transport interchange and therefore more easily encourage others to use the interchange. 


\subsection{Literature Review}

The theoretical guideline of this research is the influential Bertolini's (1996, 1999; Bertolini and Spit, 1998) node-place model, framework that provides a useful perspective to analyze the functions of public transport spaces. In this sense, we can distinguish between transport interchange and hub as transport node that decrease trip's disutility, and transport interchange as place of activities. Regarding the first aspect, contributions highlighted the perception by travelers of aspects related to infrastructure efficiency, as travel information and signs (Dell' Olio, Ibeas, Cecín, and dell' Olio, 2011; Abreu e Silva and Bazrafshan, 2013), transfer experience and accessibility (Cherry and Townsend, 2012; Guo and Wilson, 2011; Hine and Scott, 2000), and reliability and frequency (Iseki and Taylor, 2010).

From a broader perspective, it is also relevant to consider how the interchange as node fits into surrounding environment, ensuring that its design and structure is according to local networks and destinations (Monzón and Di Ciommo, 2015). Van der Hoeven et al. (2014) set out that in interchange transport area, a city should take extra care of the quality of public space leading to and from the interchange, and take care of the efficiency of bus, tram, and taxi and bike corridors serving the interchange.

\section{Transport Interchange as a place}

Regarding the place dimension, safety, security \& comfort are emerging as important components (Durmisevic and Sariyildiz, 2001; Peek and van Hagen, 2002). Comfort incorporates aspects as waiting and sitting areas, food and refreshment facilities, and comfortable seats (Van Hagen and Bron, 2014). These authors also mentioned elements then contribute to a pleased experience in affective terms, such visual aspects as architecture, design, cleanliness, used materials and colors. Respecting safety, the definition of Newton (2014) relates to "the perceptions and feelings of individual passengers and staff and their right to feel able to travel without risk or harm", while security in this context refers to "the risk levels and vulnerability of public transport systems to experience crime and disorder incidents". Ceccato and Newton (2015) concluded that safety and security in transit environments is dependent on multiscale conditions determined by the micro environmental attributes of a node (a bus stop or a station), the characteristics of the immediate environment (short walk distance from the node), the type of neighborhood in which the node is located and the relative position of both the station and the neighborhood in the city. Nevertheless, Hernandez and Monzón (2016) have noted the transversal position of Safety and Security and directly associated to the general performance of the interchange. They considered it as decisive in both node and place dimensions, paying particular attention to security aspects in transfer and waiting areas and in the surroundings of transport interchange.

Another interesting facet of transport hubs as a place is related to the concept of sense of place created in a specific social context (Alexander and Hamilton, 2015). It describes how 
communities can involvement in changing the meanings of spaces (as train stations) taking part in the introduction of physical improvements, new facilities or aesthetic appeal and in turn improving to the sense of community and attachment felt towards them. These authors argue that sense of place created by communities is important because each station, transport hub or urban centers are unique, opposing to non-places (Augé, 2008) that have lost their meaning with implementation of standardization and rationalization processes. Related to this idea, Atmodiwirjo (2008) shows how adolescents use places as public transport stations for activities beyond that designated particular functions (i.e. as a place to hang out), underlined the affordance of these casual urban places as settings for social interaction.

\section{The importance of user profile and satisfaction level}

Complementary, as remarks Bertolini (1999, p. 201) a third component of node-place model is user profile, arguing that "an accessible area is thus one where many, different people can come, but also one where many, different people can do many different things: it is an accessible node, but also an accessible place". This last component of Bertolini 's model could be integrated with traditional measures of consumer satisfaction and service quality (Gronroos, 1988; Hernon, Nitecki and Altman, 1999; Parasuraman, Zeithaml, and Berry 1985). This perspective commonly incorporated user's expectations about the service, and perceived quality results in a much broader concept where often non-technical aspects dominate the experience (Gronroos, 1988).

In the context of public transport services, certification process (UNE-EN 13186, 2003) defined the customer satisfaction measure as the difference between the level of quality which implicitly or explicitly is required by the customer ('Expected quality') and the level of quality perceived by the user ('Perceived quality'), influenced mainly by personal experience with the service. Furthermore, understanding the difference between the objective quality (e.g. performance set by the interchange managers) and subjective quality (expectations and perceptions by its users) is a priority to define adequately transport interchange service.

Recently, two papers analyses the components of transport interchange service processes and its relationship with user's satisfaction. Previously cited work of Hernandez and Monzón (2016) identify the key factors for defining an efficient transport interchange in three European transport interchanges, including Information provision and Transfer conditions as factors that facilitate the use of the interchange as a node of transport, while Design \& Image, Environmental quality, Services \& Facilities and Comfort of waiting time as more closely related to the users' experience inside an interchange as a place. These authors concluding that Safety \& Security is a key factor shared by node and place perspectives. Likewise, Hernandez, Monzón, and De Oña (2015) development a methodological framework to study transport interchanges, consisting in a new procedure of implementing 
attitudinal surveys and the application of answerthree statistical procedure to extracting derived importance of service attributes.

\subsection{Research Objectives}

To our knowledge, and after reviewing the existing literature, there are no empirical studies about the hierarchic and structural relationship between the factors described in Bertolini's model, its relation with sociodemographic or trip characteristics, or the influence of other relevant variables as waiting time on general satisfaction with interchange transport. In this sense, we can establish similarities with Durmisevic and Sariyildiz (2001) related to some design aspects of underground public spaces as subway, "the weight of the aspects is also not clear enough since it is not obvious which aspects are more important and whether they can be somehow compensated through other aspects".

Taking as starting point a sample of travelers recruited at Moncloa's transport interchange (Madrid, Spain) ${ }^{1}$, the first objective (1) of this research was to examine the predictive power of attitudes towards several service factors detected in previous works (Hernandez and Monzón, 2016) on general satisfaction with transport interchange, retaining those most relevant variables. In a second step, based on path analysis, we evaluated the relation of factors that define transport interchange as a place with Moncloa's as a node and its subsequent impact on general satisfaction (2). In this sense, we hypothesized that the influence of factors as a place on overall satisfaction is mediated by attitudes to transport as a node factors.

Also we test additional research objectives, as examining the influence of perceived waiting time on satisfaction with transport interchange (3), since this variable influences on assessment of service quality (Morfoulaki et al., 2010) and consumers usually care more about perceived than real waiting time (Wu, Lu and Ge, 2013). Nevertheless, travelers are particularly sensitive to waiting times, before, after and at interchange points when using the public transport services (Friman, 2010; Millonig, Sleszynski and Ulm, 2012), and there are psychological costs involved in the process of waiting which have been linked to anxiety and stress (Kocas, 2015; Lazarus and Folkman, 1984; Litman, 2010).

Finally, this paper analyses the influence of the users' profile and their trip patterns on their satisfaction with some aspects of urban transport interchange performance and their perceptions about the provided service quality (4).

\footnotetext{
${ }^{1}$ This sample was obtained as part of the research done in City-HUB project (EU 7th Framework Program).
} 


\section{METHOD}

It was designed a correlational study among users of a transport interchange to answer main research questions. This section shows context of the investigation, the characteristics of the sample and summarizes the procedure and research instruments used.

\subsection{Study context}

The Moncloa transport interchange (Madrid, Spain) was built in 1995. It is located on the north-west limit of the city and providing a gateway for about 300.000 people a day. The interchange was refurbished in 2008, involved an increased passenger demand, reductions in surface-level bus journeys and an improved journey times for both users and the transport companies (Aldecoa et al., 2009). The interchange is served by regional bus routes (offering over 4.000 bus journeys / day), urban bus routes (4.150 journeys / day) and hosts 3 urban lines with 53,000 people a day. Its metro station has the highest demand, to over 130.000 travelers per day (Aldecoa et al., 2009) connecting the metropolitan bus services with the city centre.

Moncloa is designed with four entrances and is distributed in four levels. Bus services are distributed in different bus bays (39) keeping separated flows of passengers and vehicles, and the design ensures that passengers do not cross or use the areas where the buses are maneuvering. Each island connects straight to the metro station entrance hall (the lowest level), travel services (information desk, ticket purchase, etc.) and the retail area.

The Moncloa interchange has high frequency of transport services and it has generally quite short transfer distances (below 200 meters); therefore, transfers can be done within 2 minutes. However, there is a lack of frequency coordination between transport operators and transport services and there is a long distance between service platforms (Hernández, 2015). While it is possible to check the time of departure based on real-time information next to boarding area of metropolitan buses, there is a lack of electric departure time displays in retail and cafe areas. On the other hand, the routes through the station are instantly visible by means of different colors on the floors, walls and ceilings, making it easier to identify different areas. The transport operators are coordinated by the PT authority, which is responsible for integrating tickets and fares for the regional public transport network in Madrid.

\subsection{Sample and procedure}

740 travelers of Moncloa transport interchange (Madrid, Spain) voluntarily completed the questionnaire. Participants were recruited data through a combined method (for a detailed description of this methodology, see Hernández, Monzón and Oña, 2015. Initially, a short face-to-face interview inside the transport interchange was conducted to users in order to 
explain them the main objectives of the survey, and next they were given a card which included a link to the on-line survey website (using SurveyMonkey platform) and control number to avoid duplication of responses. Cards were handed out by a group of four interviewers mainly in the three buses islands and at the metro entrance, on five working days and one weekend in May 2013.

It should be noted that before conducting the survey a characterization of the population by gender and age was carried out, in order to prevent bias into the sample. It was performed through a random procedure, taking notes of the five first persons every 15 minutes in the entrance/exit of the main transport modes.

As seen in Table 1, around 55\% of our participants were women, and people aged between 18 a 25 represented $44 \%$ of the sample. Most users of Moncloa interchange travel for work $(51 \%)$ or education purpose $(34 \%)$. The access to this infrastructure frequently is done by subway (53\%), while metropolitan bus is the main egress mode (60\%). Moreover, most travelers own a driving license $(72 \%)$.

Table 1. Characteristics of the sample of Moncloa transport interchange users.

\begin{tabular}{lc} 
Personal characteristics & $\%$ \\
\hline Gender & \\
Female & \\
Male & 54.1 \\
& 45.9 \\
Age & \\
18-25 years & 43.6 \\
26 - 40 years & 25.9 \\
Over 41 years & 30.4 \\
& \\
Educational level & \\
Primary & 5.0 \\
Secondary & 36.5 \\
University & 58.5 \\
Household net income & \\
Low & 41.6 \\
Intermediate & 34.5 \\
High & 23.9 \\
Driving license (Yes) & 71.9 \\
\hline
\end{tabular}

\begin{tabular}{lc} 
Trip characteristics & $\mathbf{\%}$ \\
\hline & \\
Purpose & \\
Work & 51.1 \\
Education & 34.2 \\
Leisure / family /friends & 8.8 \\
Other & 5.9 \\
& \\
Access mode & \\
Metropolitan bus & 23.5 \\
Urban bus & 13.5 \\
Subway & 52.7 \\
Walking & 10.3 \\
& \\
Egress mode & \\
Metropolitan bus & 60.4 \\
Urban bus & 13.2 \\
Subway & 17.4 \\
Walking & 8.9 \\
\hline
\end{tabular}

The travel time of the sample is around 50 minutes (for the journey to transport interchange and from transport interchange to destination, estimated by the users themselves). Travelers spend more time in commuting to work (52 minutes) or educational purposes (49 minutes), comparing with activities related with leisure o visiting family and friends (43 minutes).

On average, users spend 12 minutes inside Moncloa transport interchange. Travelers spend 
most of their time queuing $(M=7.79, S D=6.13)$, while others uses of time as transferring $(M=2.46, S D=2.72)$, sitting $(M=1.42, S D=5.03)$ or shopping or eating $(M=.60, S D=$ 2.65) are much less important.

Statistically significant differences were found regarding Queuing waiting time $(\mathrm{F}(3,736)=$ $6.02, \mathrm{p}<.001)$ and Transferring time $(\mathrm{F}(3,736)=6.85, \mathrm{p}<.001)$ on function of main egress mode. Bonferroni post hoc test shows that travelers who continue trip by metropolitan bus spend more time queuing $(M=8.60, S D=5.85)$ if we compare with those who continue by subway $(\mathrm{M}=6.39, S D=6.25)$ or by foot $(M=6.24, S D=6.89)$. Nevertheless, to take metropolitan buses mean a lesser transferring effort, as opposed to take subway $(M=2.33$, $S D=2.47$, and $M=3.20, S D=3.21$, respectively).

\subsection{Measurement scales}

Participants completed the questionnaire online from their own computers. The questionnaire consisted of three modules. The first module incorporated 37 items measuring beliefs about services attributes related with transport interchange, and users rated their satisfaction with specific items on a scale ranging from 1 (completely unsatisfied) to 5 (completely satisfied). This module also included a measure of general satisfaction with Moncloa transport interchange, measured using same scale shown previously. The second module incorporated characteristics of the trip and travel habits associated with transport interchange, and third module collected demographic variables, as basically are described in paragraph 2.2.

Following the methodology described in Hernández and Monzón (2016) seven service factors were extracted from 34 beliefs about the service, using principal components analysis with varimax rotation (60\% variance explained; KMO measure of sampling adequacy $=.95$; Bartlett's sphericity test $\mathrm{X}_{2}=14083.09, \mathrm{gl}=666, \mathrm{p}<.0001$ ). From the factor solution found were subsequently created the following seven new variables ${ }^{2}$ :

- Information. This scale includes items as "availability and ease of use of travel information (timetables, routes...) at the interchange", "accuracy and reliability of travel information displays for bus/trains/metro at the interchange". Formed by nine service attributes, the Cronbach's Alpha of all items is .85.

- Transfer conditions. These beliefs were assessed using four items, in example: "transfer distances between different transports modes. E.g.to buses, metro, taxis, cycle parking, etc.", "co-ordination between different transport operators or transport services". The reliability of the scale was 0.79 .

\footnotetext{
${ }^{2}$ The average of the scales was calculated by dividing them by the number of items on each scale, in order to enable comparisons. High scores indicate satisfaction with the specific factor.
} 
- Safety \& Security. Consists of six items (e.g. "you feel secure in the transfer \& waiting areas -during the day, evening/night-", "lighting"). These items were substantially interrelated $(\alpha=.88)$.

- Emergency situations. Was measured by four items, as "location of emergency exists" and "signposting to emergency exits", $\alpha=.90$.

- Design \& Image. Scale formed by with three items $(\alpha=.83)$ such as "the surrounding area is pleasant" or "the internal design of the interchange (visual appearance, attractiveness, etc.)".

- Environmental quality. This variable measures satisfaction related with air quality, noise, temperature and cleaning. Cronbach's Alpha of four items is .80 .

- Services \& Comfort. Users rated "number and variety of shops", "number and variety of coffee-shops and restaurants", "availability of seating" and "cash machines" (four items, $\alpha$ $=.76)$.

The above factors could be classified following the criteria showed in Hernández and Monzón (2016, p. 164, figure 2) and theoretically according to perspective of Bertollini's node-place model (1999).

\section{RESULTS}

This chapter has been structured following the researching goals. For objective 1 (examine the predictive power of attitudes towards several service factors on general satisfaction) we conducted a stepwise regression that allows to hierarch the importance of each predictor. Then, we examined trough path analysis objective 2 (the relation of factors that define transport interchange as a place and as a node), including a queuing waiting time as additional predictor (objective 3). Complementary, we conducted a GLM univariate procedure to test objective 4 , possible differences in users' profile and trip patterns related to attitudinal factors.

\subsection{Descriptive statistics and regression analysis}

Table 2 shows the descriptive statistics and correlations between the variables included in the study. General satisfaction with Moncloa Transport Interchange is about four points on average. Best evaluated service factors are Information, Safety \& Security and Design \& Image, whereas Services \& Comfort and Emergency situations are perceived less positively. General satisfaction shows significant correlations with all the variables, especially with Information scale. Information correlates most significantly with Emergency situations, Transfer conditions and Services \& Comfort, while Environmental quality is strong related with Safety \& Security and Emergency situations. Queuing waiting time (about eight minutes on average) affects negatively but moderately all variables considered, excepting 
Environmental quality and Design \& Image (not significant). Less relevant use of time inside the transport interchange, as Transferring time (about two minutes on average), Sitting time (about one minutes on average) or Shopping time (half minute on average) are not included in the table because are uncorrelated with any variable $(\mathrm{p}>.05)$.

Table 2. Means (M), standard deviations (SD) and correlations between variables $* * p<.001$

$\begin{array}{lllllllllll}M & S D & 1 . & 2 . & 3 . & 4 . & 5 . & 6 . & 7 . & 8 . & 9 .\end{array}$

\begin{tabular}{|c|c|c|c|c|c|c|c|c|c|c|c|}
\hline 1. & General satisfaction & 3.91 & .66 & . & & & & & & & \\
\hline 2. & Information & 3.74 & .67 & $.64 * *$ & - & & & & & & \\
\hline 3. & Transfer conditions & 3.69 & .71 & $.51 * *$ & $.57 * *$ & - & & & & & \\
\hline 4. & Safety \& Security & 3.74 & .76 & $.57 * *$ & $.48^{* *}$ & $.49 * *$ & - & & & & \\
\hline 5. & Emergency situations & 3.43 & .83 & $.55^{* *}$ & $.60 * *$ & $.47 * *$ & $.56^{* *}$ & - & & & \\
\hline 6. & Design \& Image & 3.77 & .76 & $.56^{* *}$ & $.55^{* *}$ & $.45^{* *}$ & $.52 * *$ & $.56^{* *}$ & - & & \\
\hline 7. & Environmental quality & 3.68 & .74 & $.55^{* *}$ & $.54 * *$ & $.47 * *$ & $.58 * *$ & $.50 * *$ & $.53 * *$ & - & \\
\hline 8. & Services \& Comfort & 3.10 & 0.78 & $.49 * *$ & $.59 * *$ & $.44 * *$ & $.44 * *$ & $.54 * *$ & $.50 * *$ & $.48^{* *}$ & - \\
\hline 9. & Queuing waiting time & 7.79 & 6.13 & $-.11 * *$ & $-.12 * *$ & $-.14 * *$ & $-.13 * *$ & $-.10 * *$ & -.06 & -.05 & $-.11 * *$ \\
\hline
\end{tabular}

A multiple regression analyses (stepwise method) were conducted to examine the effect of the seven factor services and Queuing waiting time (as independent variables) on General satisfaction with the transport interchange. Six models were extracted as the result of analysis; with standard $p$ levels of $F$ to variables to enter of .05 and $F$ to variables to remove of .10 (see Table 3).

In the first model, Information was the only variable that predicted General satisfaction. In the second model Information and Safety \& Security are the best predictors. The increased percent of explained variance in the third model is small (3\% of increase in explained variance), being included Design \& Image as significant predictor. Fourth model contains Environmental quality as new predictor (1\% of marginal increase of variance). Steps fourth to sixth provided a slightly additional explanatory effect beyond variables already included in the model, adding Emergency situations and Transfer conditions- Furthermore, Services \& Comfort $(\mathrm{p}=.39)$ and Queuing waiting time $(\mathrm{p}=.58)$ were not significant variables. 
Table 3. Regression analysis on general satisfaction with Moncloa interchange

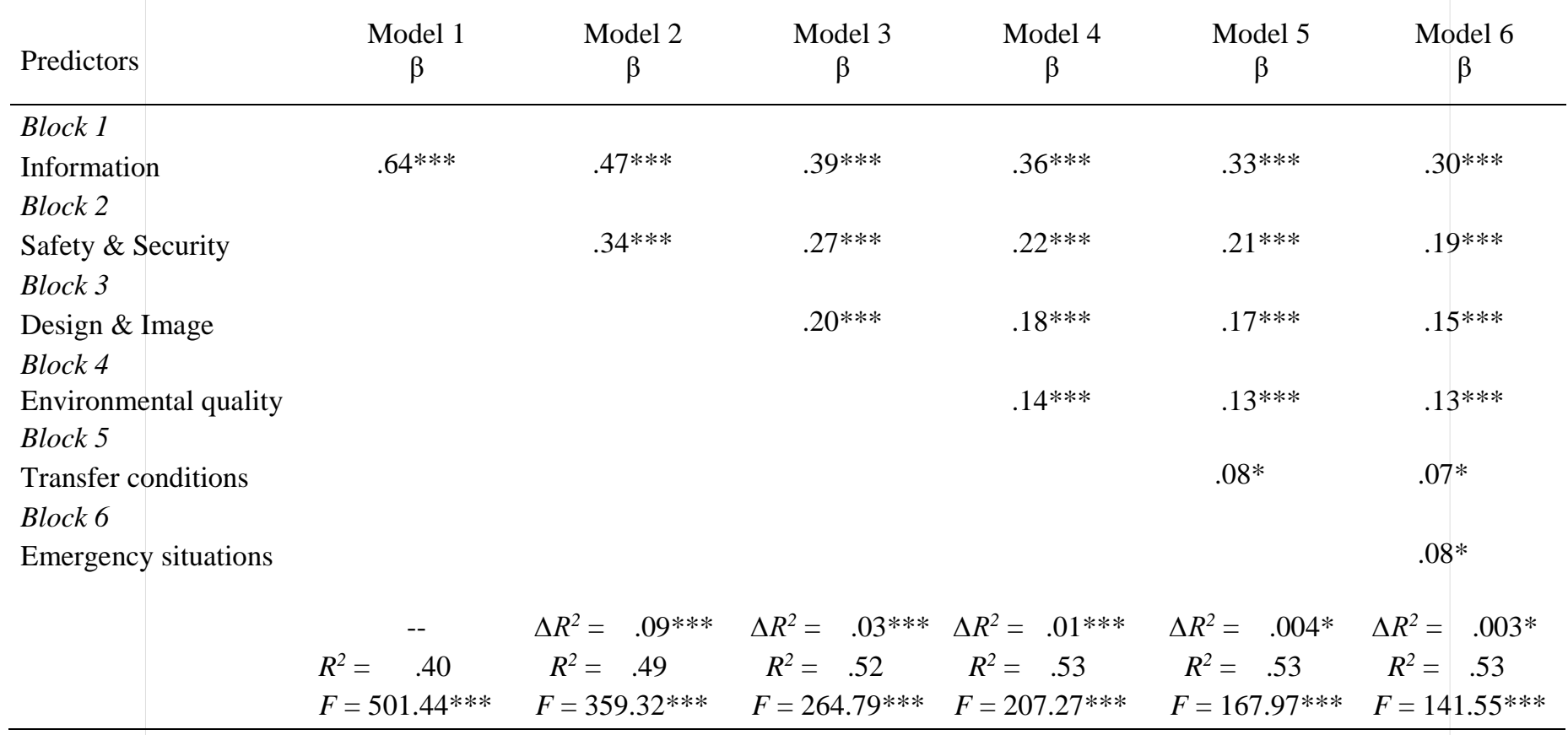

$* * * p<.001 ; * * p<.01 ; *(p<.05)$

\subsection{Path Analysis}

After checking multiple regression results, and to exam the hypothesis that variables Information (node variable) and Safety \& Security (node-place transversal variable) mediated the effect of the most relevant factors that characterize Moncloa Interchange as a place on General Satisfaction (Design \& Image, Environmental quality), we tested a model by means of path analyses with the program AMOS 20. Complementary, the model includes the effect of Queuing waiting time on Information and Safety \& Security, and the effect of age on evaluation of Information scale.

Overall model fit was acceptable $($ Chi-square $=80.04, \mathrm{df}=10, \mathrm{p}=.000 ; \mathrm{CFI}=.958 ; \mathrm{RMSEA}$ $=.097 ;$ SRMR $=.049)$ and Figure 1 shows its estimated standardized path coefficients $(\mathrm{p}<$ .001). Results indicate a strong positive relation between Design \& Image and Environmental quality, in turn main predictors of Information and Safety \& Security as hypothesized. Moreover, the model shows a weak but significant negative influence of Queuing waiting time on evaluation of Information and Safety \& Security. Additionally, analysis indicates that variable age of users influences negatively on perception of Information factor. 
Regarding determination coefficients, the model explained $28 \%$ of variance of Design \& Image factor, $41 \%$ of Information and Safety \& Security scales, and $49 \%$ of the variable General satisfaction.

\section{Figure 1. Path analysis model of factors influencing General satisfaction}

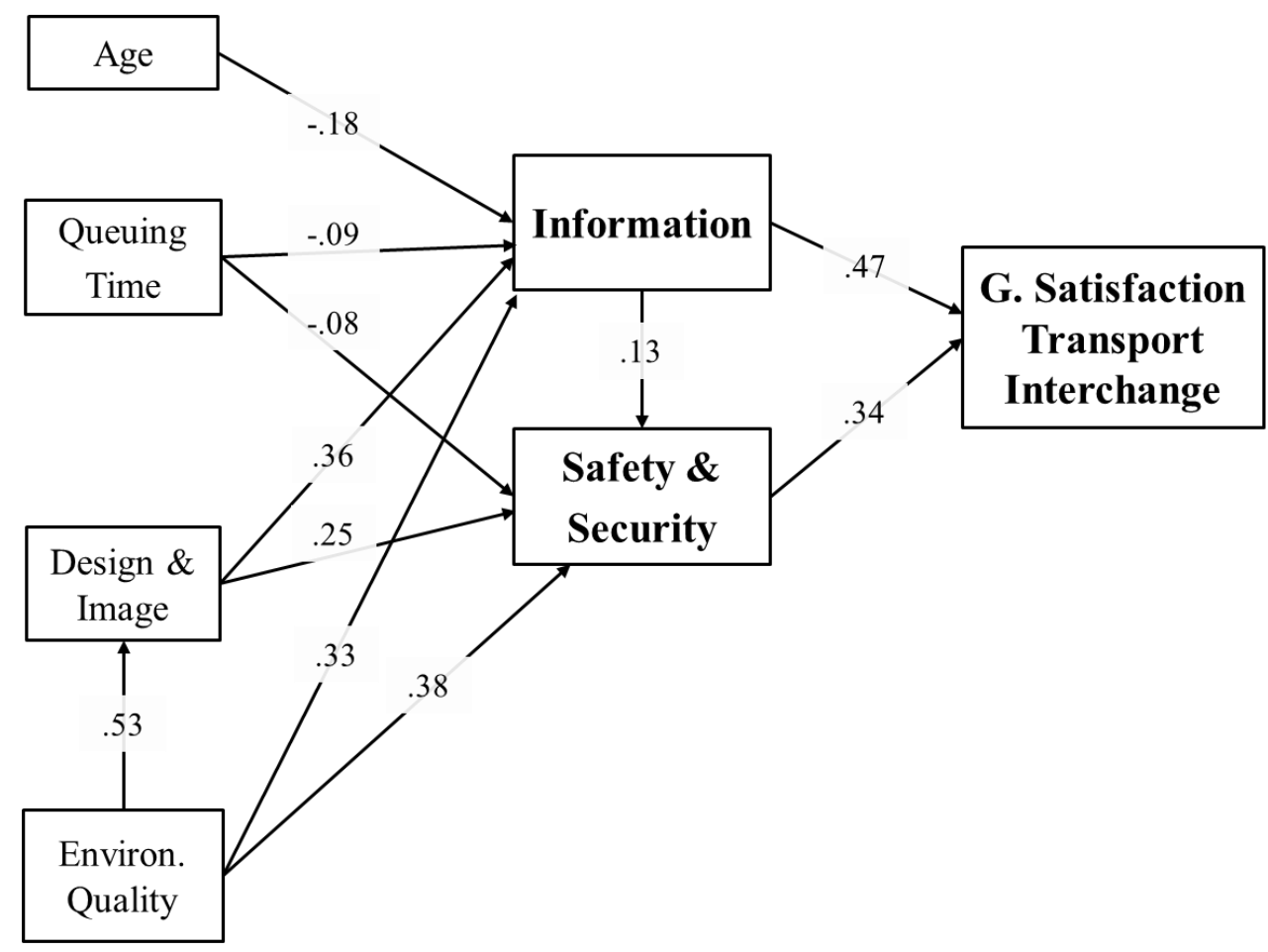

\subsection{Personal and trip characteristics and attitudes to Information and Safety \& Security}

In order to explore whether there are any difference in the perception of Information and Safety \& Security (best predictors of General satisfaction, according to the model) on function of personal characteristics (gender, age, level of education, household net income and driving license) or trip characteristics (trip purpose, main access mode and main egress mode), two univariates GLM analysis were performed.

Regarding Information, GLM analysis revealed a significant main effect for driving license $(\mathrm{F}(1,722)=11.51, \mathrm{p}<.001)$, main egress mode $(\mathrm{F}(3,722)=3.83, \mathrm{p}<.05)$, age $(\mathrm{F}(2,722)=$ 2.88 , marginally, $\mathrm{p}=.06)$, and the interaction between age and gender $(\mathrm{F}(2,722)=4.32, \mathrm{p}<$ $.05)$. Bonferroni post hoc analyses provided specific information on which means were significantly different from each other in each variable. People aged between 18 and 25 evaluate better Information factor $(M=3.95, S D=.59)$ when compared with 26-40 $(M=$ $3.77, S D=.74)$ and $41-65(M=3.76, S D=.65)$, and those without driving license $(M=3.93$, $S D=.60$ versus $M=3.73, S D=.68)$. Furthermore, travelers who continue its trip by metropolitan bus provide lower scores in this scale $(M=3.70, S D=.66$, subway $M=3.95$ $S D=.66$, and urban bus $M=3.87, S D=.61$ ). Men between 41 and 65 show lowest 
satisfaction rates $(M=3.45, S D=.64)$ especially if we compare with youngest men and women $(M=3.97, S D=.54$, and $M=3.91, S D=.62$, respectively).

Analysis of differences on Safety \& Security shows a significant effect of gender $(\mathrm{F}(1,722)$ $=3.84, \mathrm{p}<.05)$ and the interaction of gender and age $(\mathrm{F}(2,722)=5.94, \mathrm{p}<.01)$. Attitude of women towards Safety \& Security attributes is slightly worse than men's $(\mathrm{M}=3.76, S D=$ $.76, M=3.87, S D=.76)$. Women aged between 18 and 25 show lowest mean $(3.57, S D=$ $.77)$ versus men 18 to $25(M=3.94, S D=.74)$ and women of 26 to $40(M=3.85, S D=.75)$.

\section{DISCUSSION OF RESULTS}

The Transport interchange of Moncloa presents a relevant case analysis of a relatively successful transit infrastructure, under its user point of view. In this paper we have shown that modelling of factors that influence satisfaction with interchange contributes to a better knowing of most important aspects of service process. Nevertheless, at the theoretical level, our work has demonstrated the utility of Bertollini's node-place model in the analysis of satisfaction factors at urban transport interchanges.

Results show that safety perception (Safefy \& Security) and particularly, a good evaluation of information provided at the interchange (Information) are decisive variables, as predictors of satisfaction. These two variables explained half of total variance of overall perceived quality. Interestingly, both are weakly related each other, indicating that these components should be managed differentially. Receiving a good travel information when is needed is a relevant prerequisite in the decision of choosing a trip (van Hagen and Bron, 2014) and our results reinforced previous works findings based in transport interchange contexts (Abreu e Silva and Bazrafshan, 2013; Hernández and Monzón, 2016; Hernandez, Monzón, and De Oña, 2015). Where available information is evaluated as accurate and reliable, the movement of travelers through the interchange is eased. Probably this perception of the survey participants mitigates anticipatory feelings of anxiety related to the conditions of the trip (described as one of main negative emotions associated to public transportation, see Evans, Wener y Phillips, 2002; Gatersleben y Uzzell, 2007) by means of increasing its predictability.

Moreover, the model confirms a negative relation between evaluations of Information and age, and GLM analysis shows that mature men was the group with worst rating. This result may reflect the existence of some problems related to cognitive accessibility (Belinchón et al., 2014; CEAPAT, 2015) inside the interchange. This term implied that users are capable of understand correctly the meaning of the interchange environment, and possible deficits are the result of both personal skills and cognitive limitations and, on the other hand, in the information provision characteristics. On the opposite, cognitive accessibility problems can derive in orientation difficulties, emerging negative reactions as stress, anxiety frustration or ever blood's pressure increasing (Lawton, 1994; Yoo, 1991). As a derived consequence of 
this result, it would be suitable to check existing transport interchange user's information displays, panels, signposting and sightlines. This objective can be achieved by designing a specific field work, sampling among different typologies of travelers looking for best wayfinding (Arthur and Passini, 1992; Passini, 1984) strategies for each group.

Safety \& Security also emerged as critical variable. As Ceccato (2013) argued, transit system frequently is perceived as unsafe, because are unique environments compared to other settings (e.g. generating areas of social convergence that have long been associated with crime susceptibility). This is not the case of Moncloa's, but on the other hand, this does not prevent for a strong contribution of feeling of secure in the prediction of general satisfaction.

Nevertheless, our data shows gender differences in safety and security perception, since women feel less safe (particularity the youngest), and this finding is coincident with previous studies. For instance, in UK about 30 per cent of men declare feeling unsafe in transportation settings after dark, compared to 60 per cent of women (Crime Concern, 2004). A review of Loukaitou-Sideris (2009) concluded that a majority of women are fearful of the potential violence against them when in public spaces, and explanations of this fact included perceived vulnerability of women, the influence upon them of parental advice and societal admonitions, and the persistent sexual harassment that women suffer on streets and public transportation vehicles. Moreover, this author pointed out that women's fear for their safety is often amplified by media accounts that contributes to a "social production" of fear. Although the social context of our study is perhaps different (Madrid presents very high rates of public transport use and a majority of travelers of Moncloa interchange are women), is needed a deeper researcher of the reasons of worse perception of safety among women. It would also be advisable to strengthen the communication inside the interchange and surrounding, informing about present security or safety levels.

As the model demonstrated, the evaluation of Environmental Quality (air quality, noise temperature, cleaning) is closely related to attitudes towards Design \& Image elements. It is more significantly that these factors do not affect directly general satisfaction with the interchange but do so through Information and Safety \& Security perception. In this sense, measures that easing a pleasant stay of the interchange probably improve the valuation of its safety and cognitive accessibility (information provision).

The negative influence of queuing waiting time on Safety \& Security and Information factors is also noteworthy, bearing in mind than the model contains all trips purposes. It is expectable that in work trips, this relation will be stronger, because the time pressure is higher. This finding has some practical implications, recommending two ways to improve the experience of waiting in qualitative terms. Firstly, all the interchange areas should provide information about arrive and departure times (especially in the case of metropolitan buses as results showed), given that provide real time information a key for increase predictability. Secondly, transport interchange service providers should work in analyst its 
users waiting experience, attempting to improve it. Boredom decreases the evaluation of waiting areas ( $\mathrm{Wu}, \mathrm{Lu}$ and $\mathrm{Ge}, 2013)$, and seeking directly entertain the customer, or favoring conditions to benefit users when are equipped to waiting (e.g. computing, watching videos, playing video games, reading newspapers, Mishra, Mokhtarian and Widaman, 2015) will ease a positive appraisal of interchange space in emotional terms.

One main limitation of this paper is that only a transport interchange has been studied, taking into account the fact that different social norms and physical contexts are related to difference attitudes and behaviors. Future researches should replicate our results integrating several interchanges samples and including specifics characteristics of each infrastructure as control variable.

Future works also may develop a methodological framework which integrates users' needs with service providers' requirements establishing a relation between the subjective and objective quality (Hernández, 2015). It should be addressed to establish a relation between 'perceived quality' by users and the 'delivered quality' (i.e. the level of quality really achieved in the provision of mobility services), and find out the level of quality which should be provided ('targeted quality') according to the 'expected quality' by users.

Despite existing limitations and need for further research, we think that this work has demonstrated the relevance of design the transport interchange spaces according with users attitudes. A good fit between the attitudes of travelers and operation of interchange projected an image with which the traveler feels comfortable being associated with ("...am I the sort of person who goes there...), as Terzis and Last (2000) argued. This will contribute to their loyalty as user.

\section{Acknowledgements}

The authors acknowledge the financial support provided by the European Commission, as this research was possible thanks to data collected in the City-HUB project of the EU 7th Framework Programme.

\section{References}

Abreu e Silva, J., Bazrafshan, H., 2013. User satisfaction of intermodal transfer facilities in Lisbon, Portugal: Analysis with structural equations modeling. Transportation Research Record: Journal of the Transportation Research Board, 2350, 102-110. 
Aldecoa, J., Garcia, C., Ruiz, A., Lopez, S., Rodriguez, J., Criado, C., 2009. Plan de intercambiadores de Madrid. Madrid: Consorcio Regional de Transportes de Madrid (CRTM).

Alexander, M., Hamilton, A., 2015. A 'placeful' station? The community role in place making and improving hedonic value at local railway stations. Transportation Research Part A: Policy and Practice, 82, 65-77.

Arthur, P., Passini, R., 1992. Wayfinding: People, signs, and architecture. New York: McGraw-Hill Book Co.

Atmodiwirjo, P. (2008). The Use of Urban Public Places in Jakarta for Adolescents' Hanging Out. Journal of Asian Architecture and Building Engineering, 7, 339-346.

Augé, M., 2008. Non-Places: An Introduction to Supermodernity, London and New York: Verso.

Belinchón, M., Casas, S., Díez, C., Tamarit, J., 2014. Accesibilidad cognitiva en centros educativos. Madrid: Ministerio de Educación, Cultura y Deporte.

Bertolini, L., 1996. Nodes and places: complexities of railway station redevelopment. European Planning Studies, 4, 331-345.

Bertolini, L., 1999. Spatial development patterns and public transport: the application of an analytical model in the Netherlands. Planning Practice and Research, 14, 199-210.

Bertolini, L., Spit, T., 1998. Cities on rails: The redevelopment of railway stations and their surroundings. New York: Routledge.

Ceccato, V., 2013. Moving Safely: Crime and Perceived Safety in Stockholm's Subway Stations. Lexington Books.

Ceccato, V., Newton, A., 2015. Aim, Scope, Conceptual Framework and Definitions. In Safety and Security in Transit Environments (pp. 3-22). Palgrave Macmillan UK.

Centro de Referencia Estatal de Autonomía Personal y Ayudas Técnicas, CEAPAT, 2015. Análisis de la accesibilidad cognitiva, puntos críticos y propuestas de actuación en el intercambiador de transportes de Moncloa. Madrid: Ministerio de Sanidad, Servicios sociales e Igualdad.

Cherry, T., Townsend, C., 2012. Assessment of potential improvements to metro-bus transfers in Bangkok, Thailand. Transportation Research Record: Journal of the Transportation Research Board, 2276, 116-122.

COM, 2001. White Paper. European Transport Policy for 2010: Time to Decide. Office for Official Publications of the European Communities, Luxembourg. 
COM, 2006. Keep Europe moving - Sustainable mobility for our continent Mid-term review of the European Commission's 2001 Transport White Paper. Office for Official Publications of the European Communities, Luxembourg.

COM, 2008. Action Plan for the Deployment of Intelligent Transport Systems in Europe. Office for Official Publications of the European Communities, Luxembourg.

COM, 2011. White paper. Roadmap to a Single European Transport Area - Towards a competitive and resource efficient transport system. Office for Official Publications of the European Communities, Luxembourg.

Crime Concern, 2004. People's Perceptions of Personal Security and Their Concerns about Crime on Public Transport: Research Findings. Department for Transport.

Durmisevic, S., Sariyildiz, S., 2001. A systematic quality assessment of underground spaces-public transport stations. Cities, 18, 13-23.

Evans, G. W., Wener, R. E., Phillips, D., 2002. The morning rush hour predictability and commuter stress. Environment and behavior, 34, 521-530.

Friman, M., 2010. Affective dimensions of the waiting experience. Transportation research part F: traffic psychology and behaviour, 13, 197-205.

Gatersleben, B., Uzzell, D., 2007. Affective appraisals of the daily commute comparing perceptions of drivers, cyclists, walkers, and users of public transport. Environment and behavior, 39, 416-431.

Gronroos, C., 1988. Service quality: The six criteria of good perceived service. Review of business, $9,10$.

Guo, Z., Wilson, N. H., 2011. Assessing the cost of transfer inconvenience in public transport systems: A case study of the London Underground. Transportation Research Part A: Policy and Practice, 45, 91-104.

van Hagen, M., Bron, P., 2014. Enhancing the experience of the train journey: changing the focus from satisfaction to emotional experience of customers. Transportation Research Procedia, 1, 253-263.

Harmer, C., Millard, K., Palmer, D., Ubbels, B., Monzon, A., Hernández, S., 2014. What makes a successful urban interchange? Results from an evidence review. Presented at the Transport Research Arena 2014, 14-17 April in Paris. 5th TRA Conference: Transport Solutions from Research to Deployment. Available from: http://tra2014.traconference.eu/papers/pdfs/TRA2014_Fpaper_17961.pdf

Hernandez, S., 2015. Assessment methodology to make urban transport interchanges attractive for users. Doctoral dissertation, PhD Thesis. Transport Research Centre, TRANSyT-UPM, Madrid. Available from: http://oa.upm.es/38727/ 
Hernandez, S., Monzón, A., 2016. Key factors for defining an efficient urban transport interchange: Users' perceptions. Cities, 50, 158-167.

Hernández, S., Monzón, A., de Oña, R., 2015. Urban transport interchanges: A methodology for evaluating perceived quality. Transportation Research Part A: Policy and Practice.

Hernon, P., Nitecki, D. A., Altman, E., 1999. Service quality and customer satisfaction: an assessment and future directions. The journal of academic librarianship, 25, 9-17.

Hine, J., Scott, J., 2000. Seamless, accessible travel: users' views of the public transport journey and interchange. Transport Policy, 7, 217-226.

van der Hoeven, F., Aldecoa, J., Skoniezki, P., Berends, H., Venema, A., van Hagen, M., Cré, I., 2013. Report on State of the Art, Criteria and Indicators (No. Deliverable 2.3), NODES, New tools for Design and operation of Urban Transport Interchanges.

International Association of Public Transport, 2015. Public Transport Trends. Executive Summary (Retrieved from http://www.uitp.org/sites/default/files/cck-focus-papersfiles/UITP_Trends_Exec_summary_12p.pdf).

Iseki, H., Taylor, B. D., 2010. Style versus service? An analysis of user perceptions of transit stops and stations. Journal of Public Transportation, 13, 2.

Kocas, C., 2015. An extension of Osuna's model to observable queues. Journal of Mathematical Psychology, 66, 53-58.

Lawton, C. A., 1996. Strategies for indoor wayfinding: The role of orientation. Journal of Environmental Psychology, 16, 137-145.

Lazarus, R. S., Folkman, S., 1984. Stress, appraisal, and coping. Springer publishing company.

Litman, T., 2010. Transportation Cost and Benefit Analysis II-Travel Time Costs Victoria. BC: Victoria Transport Policy Institute.

Loukaitou-Sideris, A., 2009. How to ease women's fear of transportation environments: Case studies and best practices. FHWA-CA-MTI-09-2611.

Millonig, A., Sleszynski, M., Ulm, M., 2012. Sitting, waiting, wishing: Waiting time perception in public transport. In Intelligent Transportation Systems (ITSC), 2012 15th International IEEE Conference (pp. 1852-1857).

Monzón, A., Di Ciommo, F., Eds., 2015. CITY-HUBs: Sustainable and Efficient Interchange Stations. Oxford: Taylor and Francis. 
Morfoulaki, M., Tyrinopoulos, Y., Aifadopoulou, G., 2010. Estimation of satisfied customers in public transport systems: a new methodological approach. Journal of the Transportation Research Forum, 46, 1.

Newton, A. D., 2004. Crime on public transport: 'static' and 'non-static'(moving) crime events. Western Criminology Review, 5, 25-42.

NSW Ministry of Transport, 2008. Guidelines for the Development of Public Transport Interchange Facilities. New South Wales. Australia.

dell'Olio, L., Ibeas, A., Cecín, P., dell'Olio, F., 2011. Willingness to pay for improving service quality in a multimodal area. Transportation Research Part C: Emerging Technologies, 19, 1060-1070.

Parasuraman, A., Zeithaml, V. A., Berry, L. L., 1985. A conceptual model of service quality and its implications for future research. The Journal of Marketing, 41-50.

Passini, R., 1984. Spatial representations, a wayfinding perspective. Journal of environmental psychology, 4, 153-164

Peek, G. J., van Hagen, M., 2002. Creating synergy in and around stations: Three strategies for adding value. Transportation Research Record: Journal of the Transportation Research Board, 1793, 1-6.

Terzis, G., Last, A., 2000. GUIDE-Urban Interchanges: A Good Practice Guide. European Commission.

UNE-EN 13186, 2003. Transportation - Logistics and services - Public passenger transport - Service quality definition, targeting and measurement. AENOR.

Wilson, T., Yariv, B., 2011. Station Design Principles for Network Rail. Document BLDGSP80-002. (Retrieved from www.networkrail.co.uk/aspx/6368.aspx).

Wu, J. R., Lu, S. G., Ge, Y. E., 2013. Identifying Factors Impacting Customers' Perceived Waiting Time in High Density Passenger Flow Waiting Areas. Procedia-Social and Behavioral Sciences, 96, 1801-1811.

Yoo, S. Y., 1991. Architectural legibility of shopping centers simulation and evaluation of floor plan configurations. Doctoral dissertation, $\mathrm{PhD}$ Thesis. The University of Wisconsin, Milwaukee. 